\title{
EDITORIAL 26.1
}

Apresentamos o volume 26.1 de Fractal: Revista de Psicologia, com um artigo internacional e mais quatorze artigos nacionais, avaliados por consultores qualificados que participam de processo editorial paulatino e eticamente sustentado. Nossa missão se consolida todos os anos, em distintos momentos do processo editorial. Ao abrirmos o ano de 2014 com nosso atual volume, temos a valiosa notícia de que fomos contemplados por edital da FAPERJ (Fundação de Amparo à Pesquisa do Estado do Rio de Janeiro) de fomento à manutenção de periódicos científicos do estado do Rio de Janeiro, o que garantirá a resolução de uma série de problemas enfrentados pela nossa equipe no que concerne à complexificação e modernização da editoração de manuscritos científicos.

Os artigos aqui apresentados apresentam temas variados de pesquisa e reflexão. Croire em soi, croire em l'autre, de autoria de Eugene Enriquez, da Université Paris 7- Denis Diderot, abre nosso volume, seguido dos artigos $A$ pesquisa intervenção como exercício ético e a metodologia como paraskeué, de autoria de Jéssica Prudente e Jaqueline Tittoni, da Universidade Federal do Rio Grande do Sul e A história do presente em Foucault e as lutas sociais, de autoria de Kleber Prado Filho, da Universidade Federal de Santa Catarina, de Lilia Ferreira Lobo, da Universidade Federal Fluminense e de Flávia Cristina Silveira Lemos, da Universidade Federal do Pará. A seguir, temos o artigo Políticas públicas e capital social: o projeto consultório de rua, de autoria de Maria Eniana Araújo Gomes Pacheco, da Universidade Estadual do Ceará. O próximo artigo se intitula Abuso sexual, crianças e adolescentes: reflexões para o psicólogo que trabalha no CREAS, de autoria de Bruno Ricardo Bérgamo Florentino, da Universidade Federal de São João del-Rei.

A seguir, temos o artigo Identidades narrativas: construindo sentidos na travessia da juventude, de autoria de Mirela Figueiredo Iriart, da Universidade Estadual de Feira de Santana e de Ana Cecília de Sousa Bastos, da Universidade Federal da Bahia. O próximo artigo se intitula Desenvolvimento moral: vertentes pró-social e pró-ambiental, de autoria de Luana Raymundo, Maíra Longhinotti Felippe e Ariane Kuhnen, da Universidade Federal de Santa Catarina. Logo depois, há o artigo "Sempre tivemos mulheres nos cantos e nas cordas": uma pesquisa sobre o lugar feminino nas corporações musicais, de autoria de Mayara Pacheco Coelho, Marcos Vieira Silva e Marília Novais da Mata Machado, da Universidade Federal de São João del-Rei. O próximo artigo se intitula $A$ noção de alteridade radical e sua importância na docência, de autoria de Vera Lúcia Blum, da Universidade Federal de Mato Grosso.

Há, ainda, o artigo Linguagem e afetividade: a construção subjetiva da professora em suas narrativas, de autoria de Fabrícia Teixeira Borges, da Universidade Tiradentes, Ana Rita Silva Almeida, do Instituto Federal da Bahia e de Geisa Nunes de Souza Mozzer, da Universidade Federal de Goiás. O próximo artigo se intitula Escrita ensaística: fragmentos menores, de autoria de Fabiane Olegário e de Angelica Vier Munhoz, do Centro Universitário Lajeado. O artigo

Fractal, Rev. Psicol., v. 26 - n. 1, p. 1-2, Jan./Abr. 2014 
a seguir é Uma compreensão fenomenológico-hermenêutica das compulsões na atualidade, de Ana Lopes Feijoo e Carolina Freire Dhein, da Universidade do Estado do Rio de Janeiro. O próximo artigo é Retórica de influência social e negociação, segundo poder/reconhecimento na sociedade, de Edson Alves de Souza Filho, da Universidade Federal do Rio de Janeiro.

$\mathrm{O}$ artigo seguinte se intitula Escala de atitudes em saúde e estética: construção e validação e foi escrito por Everley Rosane Goetz e Brigidio Vizeu Camargo, ambos da Universidade Federal de Santa Catarina. O último artigo de nosso volume atual é Avaliação da compreensão de leitura pelo Sistema Orientado de Cloze (SOC), escrito por Maria Cristina Joly, da Universidade de Brasília, Jaqueline Bonassi, Anelise Silva Dias, Nayane Marioni Piovezan e Diego Vinícius da Silva, todos da Universidade São Francisco. Há um relato de experiência profissional intitulado Amor-ódio: devastação na relação mãe e filha, de autoria de Flavia Gaze Bomfim, da Associação Fluminense de Reabilitação.

Com melhores condições orçamentárias, esperamos manter nosso periódico operando com a qualidade e o compromisso acadêmico de toda a nossa história. Agradecemos aos colaboradores e convidamos os nossos leitores a compartilharem conosco as reflexões, problematizações e inquietações que agora se publicam em Fractal: Revista de Psicologia. Boa leitura!

\section{Marcelo S. Ferreira}

Editor de Fractal: Revista de Psicologia. 